Ensino, Saúde e Ambiente -VV5 (1), pp. 43 -62, abril. 2012

\title{
SUBSUNÇORES PARA A FÍSICA APLICADA À MEDICINA, NO CONTEXTO DO ENSINO DE FÍSICA
}

\section{SUBSUMERS FOR PHYSICS APPLIED TO MEDICINE, IN THE CONTEXT OF PHYSICS TEACHING}

\author{
Mara Fernanda Parisoto ${ }^{1}$, Marco Antonio Moreira ${ }^{1}$ e José Tullio Moro ${ }^{2}$ \\ ${ }^{1}$ Universidade Federal do Rio Grande do Sul (UFRGS) \\ ${ }^{2}$ Universidade Feevale (FEEVALE)
}

\begin{abstract}
Resumo
O presente trabalho complementa uma extensa pesquisa em artigos referentes à Física aplicada à Medicina, no contexto do ensino, em 40 periódicos CAPES, Qualis A1, A2 e B1, publicados no período de 1999 a 2009. Essa pesquisa forneceu-nos argumentos para justificar que os conhecimentos prévios, nessa área de pesquisa, são pouco investigados, tendo em vista que dos 38 artigos encontrados sobre o tema, apenas 6 referiam-se a conhecimentos prévios dos alunos, 3 de periódicos internacionais e 3 de nacionais. A partir disso, investigaram-se de forma qualitativa e quantitativa os conhecimentos prévios de um grupo de alunos do curso de licenciatura em Física da Universidade Federal do Rio Grande do Sul (UFRGS). Os resultados foram utilizados para confecção de material instrucional que foi usado em cursos para professores. Estes cursos tinham como objetivo utilizar a Física aplicada à Medicina para dar sentido a conceitos físicos, visando uma aprendizagem significativa.
\end{abstract}

Palavras chave: ensino de Física, conhecimentos prévios, Física aplicada à Medicina, aprendizagem significativa.

\begin{abstract}
This paper complements another one in which an extended review of the literature of the subject physics applied to medicine, in the context of education, was carried out in 40 journals CAPES Qualis A1, A2, and B1, published from 1999 to 2009. This review showed that this subject is quite unexplored since only 38 papers were found. Regarding student's previous knowledge only six papers were found, three in international journals and three Brazilian ones. Given this, we concluded that more research in needed in this area and decided to investigate the previous knowledge of some students majoring in physics education at the Federal University of Rio Grande do Sul (UFRGS), Brazil. The findings of this research were used in short courses for physics teachers. These courses had the purpose of using physics applied to medicine to make sense of some physics concepts aiming at meaningful learning of them.
\end{abstract}

Keywords: physics teaching, previous knowledge, physics applied to medicine, meaningful learning. 


\section{Introdução}

A Física aplicada à Medicina pode ser utilizada como facilitadora da aprendizagem significativa, tanto pela variedade de fenômenos que envolve, como pelos seus impressionantes efeitos sobre a tecnologia moderna. Assim, é recomendável seu uso em diversas áreas e, ademais, que isto ocorra cada vez mais cedo face à progressividade da aprendizagem significativa. Porém, a questão do ensino de Física aplicada à Medicina, tanto no que se refere às dificuldades para a aprendizagem de seus fundamentos, quanto ao desenvolvimento de estratégias didáticas visando facilitar este processo, é um tema de pesquisa relativamente recente na área de Ensino de Ciências. Por isto, considerou-se oportuno um estudo sobre os conhecimentos prévios que alunos de licenciatura em Física possuem, referente ao tema, tendo em vista que eles serão os futuros profissionais da educação.

Esta temática tem sido pouco investigada na área de Ensino de Física, visto que, em 40 periódicos pesquisados, na área de Ensino de Ciências, de 1999 a 2009, foram encontrados apenas 38 trabalhos versando sobre Física aplicada à Medicina, sendo 11 de periódicos brasileiros e 27 internacionais e neles apenas 6 artigos tratando sobre conhecimentos prévios.

Investigando as aplicações do Eletromagnetismo, da Óptica, da Física Moderna e Contemporânea na Medicina e os conhecimentos prévios dos alunos foi possível desenvolver uma proposta alternativa, que originou um curso, para ensinar conceitos de Física. Para tanto foi necessário compreender quais seriam, especificamente, os conteúdos do Ensino Médio que poderiam ser utilizados na Física aplicada à Medicina e, que abordagem (ns) didática(s) poderia(m) ser potencialmente facilitadora(s) da aprendizagem significativa nessa área.

A relevância didática e acadêmica deste trabalho está no fato de, a partir da análise dos conhecimentos prévios dos estudantes, ensinar de acordo, buscando aproveitar os subsunçores existentes na estrutura cognitiva dos mesmos, para que os alunos se aproximem do conhecimento científico, através de uma aprendizagem significativa e não mecânica (Ausubel, 2002; Moreira, 2005; Valadares e Moreira, 2009). 
Ensino, Saúde e Ambiente -VV5 (1), pp. 43 -62, abril. 2012

\section{Revisão da literatura sobre as concepções dos estudantes a respeito da Física aplicada à Medicina}

Na revisão feita, Parisoto, Moreira, Moro (2011), apenas três artigos de periódicos brasileiros e três internacionais relatam pesquisas com o intuito de perceber quais são os conhecimentos prévios dos estudantes referentes a um determinado assunto de Física aplicada à Medicina.

No primeiro deles, intitulado "Ondas, sonido y audición: ideas previas de los estudiantes en ciencias médicas", Aiziczon e Cudmani (2007) utilizam dois questionários, sendo o segundo mais estruturado que o primeiro, para alunos de Medicina. Tais questionários foram feitos para detectar conhecimentos prévios que poderiam constituir obstáculos e/ou subsunçores para a aprendizagem do tema. Esses resultados foram utilizados para realizar atividades que melhorassem o ensino da Física nas áreas da saúde, levando em conta as ideias prévias e os interesses dos alunos. Os autores (opt. cit., p; 3) chamam atenção para os seguintes aspectos do conhecimento prévio de Medicina em relação à Física:

- não discriminam adequadamente o agente físico onda sonora da percepção acústica;

- confundem o som como uma onda ou fenômeno físico e o som como audição;

- apresentam confusão entre onda e vibração e entre ruído e som;

- relacionam de forma equivocada a intensidade e a dor e a intensidade e a frequência para o ouvido humano.

No artigo intitulado "O ensino de Física das radiações na formação de auxiliares de enfermagem e atendentes de consultórios odontológicos: sondagem de concepções sobre Raios-X com enfoque na prevenção e tecnologia”, de Costa e Costa (2002), os autores aplicaram um questionário a 39 estudantes matriculados em um Curso de Auxiliar de Enfermagem; esse questionário era constituído de 6 questões dissertativas. A pesquisa obteve que o grupo pesquisado muito pouco sabia sobre radiações e que é necessário enfatizar esse tópico, principalmente seu uso e a forma de prevenir acidentes com os profissionais da saúde.

O terceiro artigo publicado em periódico brasileiro, intitulado "Concepções dos estudantes sobre radiações", Capelletto, Prestes e Santos (2008), descrevem uma investigação piloto que busca os conceitos que 25 estudantes de Ensino Médio têm 
sobre radiações antes da instrução, através de um questionário com 15 perguntas dissertativas. As respostas mostraram que os alunos têm noções vagas e desarticuladas sobre radiações.

Bravo e Rocha (2008) publicaram em um periódico internacional o artigo intitulado "Los modos de conocer de los alumnos acerca de la visión y el color: síntesis de resultados". Esse trabalho foi desenvolvido a partir de um estudo longitudinal de seis anos (três últimos anos do Ensino Fundamental e os três anos do Ensino Médio), tendo como objetivo estudar o modo de conhecer, sobre a visão e as cores, que compartilham um grupo de alunos conforme avança sua instrução ao longo da educação primária e secundária, encontrando indícios das concepções predominantes nos alunos ao longo de sua instrução. Para isso fez-se um estudo qualitativo (estudo de caso), aplicando antes e após cada intervenção um teste descritivo e também ao fim do Ensino Fundamental e ao término do Ensino Médio. Os testes eram formados de questões dissertativas e avaliavam as respostas em termos das variáveis (luz-objeto-sistema visual) e interações (luz-objeto: absorção-reflexão; luz-sistema visual; percepção). Depois, as pesquisadoras dividiram essas respostas em quatro categorias (ideias nitidamente intuitivas; ideias intuitivas; ideias "corretas", mas incompletas e ideias da ciência escolar). Elas concluíram que ao longo do processo de formação os alunos vão aumentando a qualificação e quantificação das respostas dadas, passando das ideias indutivas para as ideias científicas, embora não façam essa transição totalmente ao longo do período escolar.

$\mathrm{O}$ artigo "The challenge of teaching introductory physics to premedical students”, Kortemeyer (2007), propõe testes para uma turma de pré-médicos, em que lhes são feitas várias indagações com a finalidade de saber como a Física é ensinada a eles e se eles acham a disciplina importante. O autor tinha como objetivo fazer um currículo de Biofísica que ligasse conteúdos físicos às aplicações necessárias na Medicina. A sua pesquisa sugere que muitos estudantes expressam interesse em imagens médicas, exemplos de anatomia e fluxo sanguíneo e que os alunos não vêm conexão entre Física e Medicina. Para esse problema ele aponta como solução livros de texto que conectem a Física à Medicina e também a utilização, por parte do professor, de exemplos da Medicina, usando uma abordagem mais conceitual e estratégias de resolução dos problemas. Através dessa pesquisa ele sugere uma determinada ordem de abordagem de conteúdos de Física conforme mostrado na tabela 1. 
Tabela 1: ordem de conteúdos de Física aplicada à Medicina sugerida por Kortemeyer (2007).

\begin{tabular}{|l|l|}
\hline \multicolumn{1}{|c|}{ Primeiro semestre } & \multicolumn{1}{c|}{ Segundo semestre } \\
\hline Energia e trabalho & Eletrostática, campo elétrico \\
Na escala do corpo & Equilíbrio membrana \\
Momento e colisão & Capacitores \\
Relacionando com ferimentos & Desfibrilador \\
Cinemática rotacional, dinâmica rotacional & Corrente \\
Músculos & Neurônios \\
Temperatura, sólidos, líquidos e gases & O axônio \\
Placa arterial & Magnetismo; Indução \\
Aneurisma & Magnetocardiograma \\
Pressão sanguínea & Corrente variando com o tempo \\
Ossos e fratura de ossos & Marcapasso cardíaco \\
Ondas e sons & Eletrocardiograma \\
Imagem de ultrassom & Ondas Eletromagnéticas \\
O ouvido humano & Espelhos e lentes; Instrumentos ópticos \\
Ondas de choque externas ao corpo & O olho humano \\
Calor; termodinâmica & Lentes corretivas \\
Metabolismo & Cirurgia a laser nos olhos \\
& Endoscopia \\
& Interferência e difração \\
& Limitação para imagens médicas \\
& Teoria quântica \\
& Flouroscopia \\
& Microscópio eletrônico \\
& Física Subatômica \\
& Imagem na Ressonância Magnética Nuclear \\
& (RMN) \\
& Dosagem de Raios-X \\
& Radioterapia \\
& Isótopos traçadores \\
& \\
&
\end{tabular}

No último artigo que se preocupou com os conhecimentos prévios dos estudantes, intitulado "Challenges in teaching the mechanics of breathing to medical and graduate students", West (2008) comenta sobre a dificuldade e os conhecimentos prévios que os alunos de Medicina e demais estudantes de graduação possuem para entender o sistema respiratório. Tais dificuldades são originadas principalmente por tal entendimento envolver muitos conceitos físicos. Esse artigo não apresenta nem busca conhecimentos prévios, apenas cita que a metodologia de trabalho, proposta pelo artigo, visa amenizar as consequências dos conhecimentos prévios que os alunos possuem e que são contrários aos conhecimentos científicos, mas não cita quais são esses conhecimentos.

\section{Referencial teórico}

Este trabalho fundamenta-se na Teoria da Aprendizagem Significativa (TAS) de Ausubel (2002).

Segundo Ausubel, quem quer ensinar buscando facilitar, promover, uma 
aprendizagem significativa precisa descobrir o que o aluno já sabe e ensinar de acordo, pois o conhecimento prévio é a variável que mais influencia na ocorrência da aprendizagem significativa.

Para que a aprendizagem significativa ocorra é necessário que o novo conteúdo se relacione interativamente, de modo não arbitrário e não literal, com aspectos especificamente relevantes da estrutura cognitiva do ser que está aprendendo. Para Ausubel, estrutura cognitiva é "uma estrutura hierárquica de conceitos que são representações de experiências sensoriais do indivíduo" (Ausubel, 2002) e a denominação recebida por esses conceitos já presentes na estrutura cognitiva é a de "subsunçor".

A aprendizagem significativa é progressiva, ou seja, os significados são captados e internalizados progressivamente e nesse processo a interação social e a linguagem são muito importantes.

No processo de aprendizagem significativa proposta por Ausubel, um elemento muito importante é a ancoragem cognitiva, ou seja, o sujeito ao adquirir novos conhecimentos de maneira significativa, ancora internamente as informações novas em seus subsunçores.

Como afirma Ausubel:

A aprendizagem significativa envolve a interação seletiva entre o novo material de aprendizagem e as ideias pré-existentes na estrutura cognitiva. Iremos empregar o termo ancoragem para sugerir uma ligação com as ideias pré-existentes ao longo do tempo. Por exemplo, no processo de subsunção, as ideias subordinadas pré-existentes fornecem ancoragem à aprendizagem significativa de novas informações (Ausubel, 2002, p. 3).

Então, para que realmente ocorra uma aprendizagem significativa e não mecânica é fundamental considerar o conhecimento que o aluno já possui, denominado por Ausubel de subsunçores ou conhecimentos prévios, pois o conhecimento somente se constrói da interação de conhecimentos antigos e novos. O resultado deste processo Ausubel chama assimilação.

Porém, ainda, segundo Ausubel, os primeiros conceitos, ou seja, quando ainda não há subsunçor, são formados pela observação da criança e interação com outras pessoas e com o mundo. Trata-se de uma reconstrução de algo já construído pela sociedade e que apenas tem significado no âmbito social, onde é compartilhado. Esta socialização de um significado é guiada pelo uso da linguagem verbal e não verbal. 
Dessa forma, a aquisição de conhecimento depende da captação e internalização dos significados compartilhados dos conceitos envolvidos.

Quando os alunos não apresentam subsunçores, uma forma de ajudar a criá-los é através dos organizadores prévios, que assim como os diagramas $\mathrm{V}$ e os mapas conceituais, podem funcionar como estratégias facilitadoras da aprendizagem:

A fim de melhorar a aprendizagem em sala de aula, pode-se elaborar uma proposta que considere os conhecimentos prévios dos alunos buscando perceber os subsunçores que eles possuem para partir desses. Na hipótese de não haver subsunçores haverá a necessidade de produzi-los através dos organizadores prévios e sistematizando esses conhecimentos através de várias metodologias tais como os mapas conceituais e o Vê de Gowin. (Moreira, p. $25,2005)$

Os organizadores prévios são mecanismos pedagógicos que auxiliam a aprendizagem significativa, estabelecendo uma relação do que o aluno já sabe com o que o professor deseja ensinar.

Organizadores prévios são materiais introdutórios apresentados antes do material de aprendizagem em si mesmo, em um nível mais alto de abstração, generalidade e inclusividade, utilizados como ponte entre o que o aprendiz já sabe e o que deveria saber para que esse material fosse potencialmente significativo ou, mais importante, para mostrar a relacionabilidade do novo conhecimento com o conhecimento prévio (Moreira, p. 16, 2005).

Os mapas conceituais ${ }^{1}$ são diagramas que apresentam hierarquias e relações entre conceitos, procurando refletir a estrutura conceitual de certo conhecimento através deles. Segundo Moreira (2005), apresentá-los, construí-los, refazê-los, discutir sobre eles, são processos que facilitam a aprendizagem significativa.

Os diagramas $\mathrm{V}^{1}$ são utilizados para analisar o processo de construção do conhecimento. Assim como nos mapas conceituais, apresentá-los, construí-los, refazêlos, discutir sobre eles, são processos que promovem a aprendizagem significativa.

Um subsunçor pode estar em oposição a um dado conteúdo, mas ser importante para o sujeito, por isso, é necessário compreender os subsunçores que o sujeito possui.

Segundo (Ausubel, 2002) o processo de detalhamento, refinamento e especificidade de um subsunçor é denominado princípio da diferenciação progressiva. Neste, parte-se do geral (mais abrangente, mais importante) rumo ao específico (trabalhando através de exemplos, exercícios, situações) em um processo de ida e volta. Já a exploração das ligações entre conhecimentos, recombinando e relacionando

\footnotetext{
${ }^{1}$ Para maiores informações a respeito ver Novak e Gowin (1984).
} 
significados, onde buscam-se diferenças e semelhanças entre o conhecimento, é conhecido por reconciliação integradora.

Segundo Ausubel (2002), partindo dessas relações, pode-se intervir para modificar um subsunçor, tornando-o adequado para que a ancoragem ocorra significativamente, ou mesmo construí-lo, caso não exista. Outro fator muito importante para que ocorra a aprendizagem significativa é que o aluno esteja pré-disposto a aprender. Ou seja, deve apresentar uma intencionalidade.

\section{Contextualização}

A intervenção, referida neste artigo, faz parte de uma pesquisa de Mestrado em Ensino de Física, resultado da primeira aplicação do material produzido, possuindo, por tanto, um caráter de experiência piloto. A experiência piloto foi realizada em 6 sábados, em períodos de quatro horas cada, totalizando 24 horas de um curso utilizando a Física aplicada à Medicina para dar sentido a conteúdos de Óptica, Eletromagnetismo, Física Moderna e Contemporânea.

\section{Metodologia}

O grupo, que fez parte dessa primeira aplicação, esteve formado por 12 alunos da Universidade Federal do Rio Grande do Sul (UFRGS) e dois professores. Do grupo de alunos, 8 são da Licenciatura em Física, sendo que destes, 7 são bolsistas do Programa Institucional de Bolsa de Iniciação à Docência (PIBID), um da Geologia, um da Engenharia de Minas, um que faz Mestrado em Ensino de Física e um aluno da Filosofia. Os alunos que não são do curso de física são bolsistas do Serviço de Proteção Radiológica (SPR), ou seja, utilizam muitos conceitos físicos no seu trabalho. O aluno de Mestrado em Ensino de Física, assim como os professores, participou do curso, principalmente, para fornecer importantes contribuições. Dessa forma, todos os participantes já possuíam conhecimentos prévios sobre alguns conceitos que foram trabalhados no curso.

Foi desenvolvido um material de apoio potencialmente significativo para aumentar as possibilidades de aprendizagem significativa. A cada etapa, o material era alterado e, conforme necessário melhorado. Esse material foi dividido em cinco partes que compunham cinco aulas. Cada aula possuía a seguinte estrutura em ordem cronológica: $1^{\circ}$ ) organizador prévio; $2^{\circ}$ ) gravação em áudio, utilizando o software 
Audacity, da discussão realizada em grupos pelos alunos, de uma situação-problema que era apresentada a eles no início da aula; $3^{\circ}$ ) aula expositiva intercalada com atividades diferenciadas, por exemplo: mapas conceituais, atividades experimentais, filmes, resolução de exercícios, apresentações, discussões, simulações e modelagens computacionais; $4^{\circ}$ ) gravação em áudio, utilizando o software Audacity, das discussões feitas pelos alunos a mesma situação-problema apresentada a eles no início da aula.

Todas as aulas foram planejadas a partir dos conhecimentos prévios catalogados na literatura e também a partir das respostas dadas pelos alunos a um questionário que visava descobrir alguns subsunçores que os mesmos possuíam sobre os assuntos a serem trabalhados. Desta forma, se os alunos mostravam desconhecimento sobre algum assunto, esse era mais enfatizado nas explicações e se mostravam conhecimento sobre algum tema, esse era utilizado para a ancoragem dos conhecimentos a serem ensinados no curso.

O foco deste artigo está neste questionário, a fim de compartilhá-lo com a comunidade, não na intervenção didática.

No início da primeira aula foi aplicado o questionário descrito a seguir, contendo 29 questões de múltipla escolha. Antes da sua aplicação, foi calculada a fidedignidade do questionário e foi feita a validação de conteúdo.

\section{Questionário}

O questionário elaborado possuía, inicialmente, 37 questões envolvendo as seguintes aplicações: ultrassonografia, funcionamento da radiografia convencional e da mamografia, fluoroscopia, fluoroscopia digital, imagem radiográfica, teleterapia, braquiterapia, Tomografia Computadorizada (TC), Tomografia Computadorizada Helicoidal (TCH), Ressonância Magnética Nuclear (RMN), detectores de radiação, Medicina Nuclear, Tomografia por Emissão de Pósitron (PET) e Tomografia por Emissão de Fóton Único (SPECT).

Esse questionário foi entregue para 4 professores da UFRGS para que fizessem a validação de conteúdo. Foram aceitas as várias modificações e correções sugeridas.

Posteriormente, o mesmo foi enviado para várias pessoas formadas em Física, professores e alunos de licenciatura em Física, sendo que 16 responderam. Em seguida, foi calculado o coeficiente alfa de Cronbach e foi encontrado um valor de 0,796 para as 37 questões. Foram então retiradas 8 questões que apresentavam baixa correlação com 
as demais e assim obteve-se um coeficiente de Cronbach de 0,865. Entretanto, segundo Silveira e Moreira (1989), para que o valor do alfa de Cronbach seja pouco influenciado por flutuação estatística, é desejável que o número de respondentes seja de, pelo menos, cinco vezes maior do que o número de questões. Então aplicou-se novamente o questionário para 250 pessoas entre professores da Rede Estadual de Santa Catarina e alunos matriculados nas Físicas Básicas da UFRGS, ou seja, mais do que cinco vezes o número de questões. O coeficiente de Cronbach encontrado foi 0,864 que segundo Vianna (1978, p. 145, apud Moreira \& Rosa, 2002) é bastante adequado para um instrumento dessa natureza.

\section{Conhecimentos iniciais}

Dos 12 alunos inscritos apenas três foram até o final. Acredita-se que tal evasão tenha ocorrido devido a ser final de semestre, por ser no sábado de manhã, por haver um feriado em uma sexta-feira e por ter havido três sábados muito chuvosos. Foi escolhido o sábado pela manhã, porque foi o único horário em que os alunos inicialmente não tinham outros compromissos.

No primeiro dia de aula houve apenas 5 participantes, a partir das respostas deles foi feita a análise descrita na seção 8, considerando as seguintes categorias:

1. Produção de radiação: questões 1 e 2 .

2. Interação da radiação com a matéria: questões 3 e 4 .

3. Aparelho de Raios-X e Mamógrafo: questões 5 e 6.

4. Meios de Contraste: questão 7.

5. Fluoroscopia: questões 8, 9 e 10.

6. Formação das imagens radiográficas: questões 11, 12, 13 e 14.

7. Radioterapia: questões 15 e 16.

8. Dosímetros: questões 17, 18, 19, 20, 21 e 22.

9. Tomografia: questão 23.

10. RMN: questões 24 e 25 .

11. Medicina Nuclear: questões 26, 27, 28 e 29.

A seguir o questionário é apresentado na íntegra para que fique mais clara a análise feita e para que outros pesquisadores possam utilizá-lo em suas pesquisas. 


\section{Questionário aplicado ${ }^{2}$}

Produção de radiação: questões 1 e 2.

1) Quando elétrons são retirados da eletrosfera do átomo (p. ex. por uma captura eletrônica), a vacância originada é imediatamente preenchida por um elétron de orbitais inferiores. Esse elétron, ao passar de um estado mais ligado para outro menos ligado (mais próximo do núcleo), libera o excesso de energia emitindo radiação eletromagnética, cuja energia é igual à diferença entre a energia dos estados inicial e final. Esse processo é chamado de produção de radiação característica.

a) Concordo.

b) Discordo. $\mathbf{X}$

c) Não sei.

2) Um elétron (negativo), ao passar nas proximidades de um núcleo (positivo), experimenta uma força de atração elétrica e é desviado de sua direção original. Ao variar de direção, o elétron perde energia cinética. A energia cinética perdida pelo elétron é emitida na forma de um fóton. O processo descrito é chamado de emissão de radiação por freamento.

a) Concordo. $X$

b) Discordo.

c) Não sei.

Interação da radiação com a matéria: questões 3 e 4.

3) No efeito Compton, diferentemente do efeito fotoelétrico, o elétron não possui energia suficiente para se desprender do átomo, ele apenas absorve toda ou parte da energia do fóton. Quando o elétron absorve toda a energia do fóton, ele muda para uma camada mais externa. Ao retornar, o elétron emite a radiação absorvida. Quando absorve apenas parte da radiação, há duas ondas: uma decorrente da mudança de camada e outra devido ao desvio da radiação incidente, ocasionada pela incidência do fóton no elétron, conforme previsto pela conservação do momento angular.

a) Concordo.

b) Discordo. $\mathrm{X}$

c) Não sei.

4) Os processos de aniquilação e produção de pares surgiram da necessidade de se explicar os resultados da equação de Dirac, que tem como soluções uma energia negativa e uma energia positiva. Dirac assumiu que os níveis de energia negativa estavam todos ocupados, de modo que os elétrons de energia positiva não poderiam cair em um "buraco" da energia negativa. Esse "buraco" de energia negativa é interpretado como uma antipartícula (antimatéria), por exemplo, um pósitron. $O$ processo inverso pode ocorrer, se um elétron de energia positiva cair em um "buraco"; nesse caso seria emitido um fóton e o elétron seria aniquilado pelo "buraco".

a) Concordo. $X$

b) Discordo.

c) Não sei.

Aparelhos de Raios-X e mamógrafo: questões 5 e 6.

5) Se tivermos duas bobinas, elas vão funcionar a partir do seguinte processo: corrente elétrica alternada na primeira bobina gera um campo magnético variado na segunda bobina, que, por sua vez, produz nela uma corrente elétrica alternada.

a) Concordo. $X$

b) Discordo.

c) Não sei.

6) Em uma máquina de Raios-X, um feixe de elétrons sai do cátodo (negativo) e parte em direção ao ânodo (positivo). A diferença de potencial entre eles $(\mathrm{kVp})$ deve ser muito grande para que a energia dos elétrons seja suficiente para produzir Raios-X ao atingirem o ânodo. Para que o

\footnotetext{
2 as respostas marcadas com " $X$ ” são as alternativas corretas.
} 
ânodo não derreta, ele está em constante movimento e ainda é resfriado por um óleo frio. Todo o conjunto é envolvido por uma ampola, que mantém o sistema em vácuo, evitando que haja perdas de energia para o meio.

a) Concordo. $\mathbf{X}$

b) Discordo.

c) Não sei.

Meios de contraste: questões 7.

7) O meio de contraste, utilizado em alguns exames de Tomografia Computadorizada (T.C.), é uma substância geralmente líquida, injetada ou ingerida pelo paciente para bloquear a radiação, possuindo densidade diferente do material a ser estudado, pois não se pode distinguir uma estrutura de outra se ambas possuírem a mesma densidade radiográfica. Já na Ressonância Magnética Nuclear (RMN), os meios de contraste alteram o campo magnético de uma parte específica do corpo.

a) Concordo. $X$

b) Discordo.

c) Não sei.

Fluoroscopia: questões 8, 9 e 10.

8) A principal função do fluoroscópico é proporcionar imagens (dinâmicas) em tempo real de estruturas anatômicas e, com isso, visualizar estruturas e líquidos internos em movimento.

a) Concordo. $\mathbf{X}$

b) Discordo.

c) Não sei.

9) No intensificador, a imagem é produzida de acordo com a seguinte sequência: fótons de luz são transformados em fótons Raios X, que geram corrente elétrica e esta em imagem visível.

a) Concordo.

b) Discordo. $X$

c) Não sei.

10) A fluoroscopia trabalha com doses de radiação maiores do que as demais máquinas de Raios $X$, dessa forma, embora o tempo de exposição seja o mesmo, as doses de radiação que chegam aos pacientes são maiores na fluoroscopia.

a) Concordo.

b) Discordo. $\mathrm{X}$

c) Não sei.

Formação de imagens radiográficas: questões 11, 12, 13 e 14.

11) Quando se aumenta o valor do $\mathrm{kVp}$ (diferença de voltagem entre o cátodo e o ânodo na máquina de Raios $X$ ), aumenta-se também a energia dos Raios $X$ e, consequentemente, a capacidade de penetração da radiação no paciente, afetando com isso o contraste da imagem. Para valores baixos de $\mathrm{kVp}$, os fótons não possuem energia suficiente para atravessar o paciente, sendo absorvidas, o que requer uma maior dose de radiação. Portanto, mantido o mesmo valor para a corrente elétrica (medida em miliampères), quanto menor o valor de $\mathrm{kVp}$, mais clara será a imagem, para exames de Raios-X convencional.

a) Concordo. $X$

b) Discordo.

c) Não sei.

12) Os Raios $X$ chegam inicialmente ao écran, uma película que, em contato com os Raios $X$, produz luz visível que impressiona o filme onde a imagem é produzida. $O$ filme é protegido pelo chassi radiográfico, que impede que o filme seja sensibilizado por outras radiações.

a) Concordo. $X$

b) Discordo.

c) Não sei.

13) Se o tecido orgânico tiver maior densidade, a imagem será mais escura, em exames de Raios-X convencional e, portanto, terá maior densidade radiográfica. Os fótons que são atenuados ou 
espalhados atingirão o écran com maior intensidade em função da espessura do paciente e da densidade do tecido, produzindo assim uma imagem com diferentes níveis de cinza.

a) Concordo.

b) Discordo. $X$

c) Não sei.

14) O contraste é definido pela diferença entre a densidade óptica dos objetos. Os componentes que podem ser radiografados são músculos, fluidos, tecido adiposo, gases e ossos, sendo que os três primeiros possuem densidades similares e, por isso, possuem pouco contraste na imagem radiográfica.

a) Concordo. $\mathbf{X}$

b) Discordo.

c) Não sei.

Radioterapia: questões 15 e 16.

15) A radioterapia é um método de tratamento que consiste na destruição de células cancerígenas, em especial na fase de multiplicação celular, utilizando radiações ionizantes eletromagnéticas (Raios X e raios gama) e radiações corpusculares (partículas alfa e beta), que são de elevada frequência e, consequentemente, mais energéticas. A radioterapia é dividida em dois tipos: teleterapia (externa) e braquiterapia (interna).

a) Concordo. $\mathbf{X}$

b) Discordo.

c) Não sei.

16) Aceleradores são túneis circulares que servem para acelerar partículas até que elas atinjam energias muito elevadas e possam emitir, além de Raios $\mathrm{X}$, feixes de elétrons e nêutrons com várias energias. Um exemplo de acelerador é o cíclotron e um dos mais conhecidos cíclotrons da atualidade é o LHC (Grande Colisor de Hádrons). Os aceleradores não possuem material radioativo no seu interior.

a) Concordo. $\mathrm{X}$

b) Discordo.

c) Não sei.

Dosímetros: questões 17, 18, 19, 20, 21, 22.

17) Um detector a gás é constituído de um tubo cheio de gás, em que existe um eletrodo ao longo do eixo central. Se for criada uma diferença de potencial entre o eletrodo central e a parede, de maneira que o eletrodo seja positivo e a parede negativa, então o eletrodo atrairá os elétrons produzidos por ionização dentro do tubo. Os elétrons formarão um sinal elétrico, como um pulso de elétrons ou uma corrente contínua. O sinal elétrico é amplificado e medido. Sua intensidade é proporcional à intensidade da radiação que o causou.

a) Concordo. $X$

b) Discordo.

c) Não sei.

18) Os detectores de cintilação são formados por alguns materiais que emitem luz depois de algumas horas de terem absorvido um fóton de Raios X. A quantidade de luz emitida é inversamente proporcional à quantidade de energia absorvida pelo material.

a) Concordo.

b) Discordo. $\mathrm{X}$

c) Não sei.

19) Os dosímetros termoluminescentes são constituídos de um material que, ao ser submetido ao calor, libera a energia excedente (gerada, p. ex., pelo contato com radiação). Essa energia emitida é medida e seu valor indica a quantidade de radiação a que o dosímetro foi exposto.

a) Concordo. $X$

b) Discordo.

c) Não sei.

20) No processo de luminescência estimulada opticamente, a irradiação do óxido de alumínio estimula alguns elétrons a um estado excitado. Durante o processo, uma luz laser estimula estes 
elétrons, fazendo com que voltem ao estado original, com a consequente emissão de luz visível. $\mathrm{A}$ intensidade da luz é proporcional à dose de radiação recebida.

a) Concordo. $\mathbf{X}$

b) Discordo.

c) Não sei.

21) Os detectores de estado sólido são formados por um material à base de fósforo que cintila (emite luz) pela passagem da radiação. A luz incide no núcleo do detector e emite elétrons (efeito fotoelétrico), dando origem a uma corrente elétrica que é inversamente proporcional ao fóton (radiação) incidente.

a) Concordo.

b) Discordo. $\mathbf{X}$

c) Não sei.

22) No dosímetro de filme, a radiação produz alterações na densidade do filme revelado. Desta forma, pode-se quantificar a exposição da radiação, pois quanto menor for a intensidade da radiação, maior será o enegrecimento da imagem.

a) Concordo.

b) Discordo. $\mathrm{X}$

c) Não sei.

Tomografia Computadorizada: questão 23.

23) Na tomografia computadorizada helicoidal, ao contrário da tomografia computadorizada, o emissor de radiação e os detectores fazem uma volta completa de $360^{\circ}$ ao redor do paciente. Para isso, os cabos de fibra óptica foram substituídos por anéis deslizantes. Uma superfície é um anel liso e a outra é um anel com contatos eletrônicos que rastreiam as informações do anel liso. Essas informações geralmente são emitidas por radiofrequência.

a) Concordo. $\mathbf{X}$

b) Discordo.

c) Não sei.

Ressonância Magnética Nuclear: questões 24 e 25.

24)A Ressonância Magnética, também chamada de Ressonância Magnética Nuclear, é um exame moderno que utiliza radiação ionizante, raios gama, que são produzidos no núcleo, por isso o nome nuclear.

a) Concordo.

b) Discordo. $X$

c) Não sei.

25) A Ressonância Magnética Nuclear faz uso de campos magnéticos e radiofrequência. Na ausência de um campo magnético externo, a orientação dos spins nos tecidos é aleatória. Quando o magneto principal aplica um campo magnético, o vetor momento magnético se alinha com o campo (estado de equilíbrio). Ao se aplicar sobre os spins uma radiofrequência, eles ganham energia e mudam de orientação (estado fora de equilíbrio). Cessando o estímulo, os spins retornaram ao alinhamento original, liberando a energia sob a forma de ondas de radiofrequência, que são captadas pelas antenas receptoras.

a) Concordo. $X$

b) Discordo.

c) Não sei.

Medicina Nuclear: questões 26, 27, 28 e 29.

26) A Medicina Nuclear consiste na administração de radiofármaco. Um radiofármaco incorpora dois componentes: um radioisótopo (partícula emissora de radiação beta, alfa e gama) e uma molécula orgânica com fixação preferencial em determinado tecido ou órgão.

a) Concordo. $X$

b) Discordo.

c) Não sei. 
27) Os radioisótopos usados na medicina nuclear decaem em questão de dias, horas ou até mesmo minutos, têm níveis de radiação maiores que os Raios $X$ e que as tomografias computadorizadas e são eliminados pela urina ou pelas fezes.

a) Concordo.

b) Discordo. $\mathrm{X}$

c) Não sei.

28) Na Tomografia por Emissão de Pósitrons (PET), utiliza-se um radioisótopo emissor de pósitrons. Ao se chocarem, o pósitron e o elétron aniquilam-se, emitindo dois raios gamas.

a) Concordo. $\mathrm{X}$

b) Discordo.

c) Não sei.

29) Na tomografia PET há a emissão de dois raios gama enquanto que na SPECT ocorre a emissão um único raio gama.

a) Concordo. $\mathbf{X}$

b) Discordo.

c) Não sei.

\section{Análises e discussões}

Inicialmente serão apresentadas as análises das questões em que não houve equívocos pelos alunos.

Nas questões 1 e 2 houve 4 acertos cada uma e apenas um aluno afirmou não saber cada uma das questões.

Pode-se observar que as duas formas de produção de radiação: freamento e característica são bem conhecidas por quatro dos cinco alunos, portanto eles apresentam conhecimentos prévios científicos referentes a esse assunto.

Na questão 5 todos os alunos responderam corretamente. Esta questão refere-se a conhecimentos de indução eletromagnética, que é muito utilizada no Ensino Médio e não se relaciona diretamente a Física aplicada à Medicina, mas ao principio de funcionamento do gerador, justificando assim que todos os alunos acertaram a resposta a essa questão.

$\mathrm{Na}$ questão 7 quatro alunos responderam corretamente e apenas um respondeu que não sabia a informação. Nessa questão também ocorreu da maioria saber a resposta, devido às relações existentes entre meios de contraste e a densidade (conceito trabalhado no Ensino Médio e Superior).

$\mathrm{Na}$ questão 22 três alunos relacionaram de forma correta a intensidade da radiação com o enegrecimento da imagem e dois desconheciam o assunto.

Nas questões 11 e 12 houve apenas um aluno que não sabia; os demais conseguiram relacionar de forma correta a intensidade da voltagem no tubo de Raios-X 
com a dose absorvida pelo paciente, relacionando corretamente a relação entre a voltagem e a intensidade da radiação que atravessa o paciente.

Na questão 13 dois alunos não sabiam a resposta, os demais conseguiram relacionar a densidade do tecido e sua relação com a imagem, sabendo que quanto maior for a densidade mais clara será a imagem produzida.

Na questão 15 dois alunos não souberam responder e na questão 16 apenas um. $\mathrm{Na}$ primeira, os alunos demonstraram que sabiam o que é radioterapia, quais são os elementos usados para realizá-la e como ela é dividida: teleterapia e braquiterapia. $\mathrm{Na}$ segunda, demonstraram que sabiam sobre o funcionamento de um cíclotron, sobre sua função e sobre a informação que não utilizam material radioativo em seu interior.

$\mathrm{Na}$ questão 24 dois alunos afirmaram não saber e três responderam corretamente. A maioria dos alunos demonstrou saber que a Ressonância Magnética Nuclear não usa radiação ionizante, mas sim um forte campo magnético associado à radiofrequência.

Passa-se agora a analisar as questões que não apontam a existência de conhecimentos prévios pelos alunos.

$\mathrm{Na}$ questão 3 haviam duas respostas corretas, uma errada e dois alunos afirmaram desconhecer o assunto. Essas respostas mostraram que há uma confusão entre efeito fotoelétrico e efeito Compton e também um desconhecimento desse assunto por parte da maioria dos alunos.

A questão 4 abordou a criação e a aniquilação de pares, três alunos afirmaram não saber, um acertou e outro errou. Esses dados também indicaram que há pouco conhecimento desse assunto pelos alunos.

A questão 6 refere-se à produção de Raios-X em uma máquina; dois alunos responderam que não sabiam, nenhum acertou e três responderam equivocadamente, mostrando a importância de abordar mais profundamente e extensamente este tópico no curso.

Nas questões 8 e 9 dois alunos responderam corretamente e três responderam que não sabiam sobre o assunto. A primeira questão forneceu indícios que três alunos não possuíam conhecimentos sobre o funcionamento do fluoroscópico e a segunda que três alunos não tinham conhecimentos sobre o funcionamento do intensificador de imagens. 
Apenas um aluno acertou à questão 10, os demais responderam que não sabiam, fornecendo indícios de que quatro alunos desconheciam a relação existente entre o equipamento da fluoroscopia e a dose de radiação a que o paciente é exposto.

$\mathrm{Na}$ questão 14 três alunos não sabiam a resposta, sugerindo que a maioria dos alunos não sabiam a diferença entre densidade óptica e densidade dos tecidos, quais são os tecidos que podem ser radiografados e as relações entre densidade e contraste.

Nas questões 17 e 20 todos afirmaram desconhecer o assunto, mostrando a importância de abordar com mais profundidade o funcionamento dos detectores a gás e dos detectores que funcionam a partir da luminescência estimulada opticamente.

Nas questões 18 e 21 apenas um aluno respondeu corretamente, os demais afirmaram que não sabiam. Este resultado forneceu indicativos da importância de utilizar um tempo maior para ensinar sobre os detectores do estado sólido e de cintilação.

$\mathrm{Na}$ questão 19 dois alunos acertaram e três não souberam responder, fornecendo indícios de que se deve dar ênfase para o funcionamento dos dosímetros termoluminescentes ao longo do curso.

Na questão 23 dois alunos responderam de forma incorreta, dois afirmaram não saber e um acertou a questão. Acredita-se que os alunos que erraram provavelmente confundiram os diversos tipos existentes de tomografia, pois as tomografias computadorizadas anteriores a helicoidal não fazem uma volta de $360^{\circ}$ em torno do paciente, mas sim de $180^{\circ}$. Esse assunto também mereceu maior ênfase durante a aplicação do curso.

Na questão 25 dois alunos responderam corretamente e três não souberam responder, justificando a importância de ser mais enfatizado o funcionamento do aparelho da RMN, utilizando seu funcionamento para dar sentido aos conceitos físicos envolvidos.

Nas questões 28 e 29 todos os alunos afirmaram não saber a resposta, ou seja, há indícios de que os alunos não possuíam conhecimentos relacionados à PET e a SPECT.

$\mathrm{Na}$ questão 26 apenas um aluno acertou, os demais afirmaram desconhecer o assunto, mostrando a importância de ser enfatizado, durante o curso, como são formados os radiofármacos, que é formado por um radioisótopo e uma molécula orgânica com fixação preferencial em determinada parte do corpo. 
Por fim, a análise da questão 27 sugeriu que a maioria dos alunos (3) não sabem que os radioisótopos liberam ondas eletromagnéticas com energia menor do que a TC e do que as tomografias computadorizadas e são eliminados pela urina e/ou pelas fezes. Dois alunos acertaram essa questão.

Resumindo, esse teste inicial forneceu indícios de quais são os conhecimentos bem estruturados na estrutura cognitiva dos alunos e os conhecimentos que há necessidade de enfatizar na aplicação do curso. Tais conhecimentos estão na síntese a seguir. Antes, cabe destacar que uma análise feita com respostas de apenas cinco alunos é apenas ilustrativa. Certamente qualquer análise quantitativa requereria muito mais alunos. Contudo, como já foi dito, o objetivo deste trabalho é disponibilizar o questionário que foi devidamente validado e fidedigno.

Conhecimentos prévios dos quais encontrou-se indícios que já estão presentes na estrutura cognitiva da maioria dos alunos: duas formas de produção de radiação: freamento e característica; indução eletromagnética; meios de contraste; densidade; intensidade da radiação com relação ao enegrecimento da imagem; relação entre voltagem na máquina de Raios-X, a intensidade do feixe e a dose de radiação absorvida pelo paciente; relação entre densidade do tecido orgânico e a produção de imagem; proporcionalidade da densidade do tecido e da correspondente imagem produzida; o que é radioterapia, quais são os elementos usados para realizá-la e como ela é dividida; o funcionamento de um cíclotron, sua função e que não utilizam material radioativo em seu interior; a RMN não usa radiação ionizante, mas sim um forte campo magnético associado a ondas de radiofrequência.

Conhecimentos dos quais encontrou-se indícios que são necessários enfatizar: Efeito Compton, semelhanças e diferenças com o Efeito Fotoelétrico; aniquilação e produção de pares; produção de Raios-X em uma máquina; funcionamento do fluoroscópico; funcionamento do intensificador de imagens; relação entre a fluoroscopia e dose de radiação ao paciente; diferença entre densidade óptica e densidade dos tecidos; quais são os tecidos que podem ser radiografados e as relações entre densidade e contraste; o funcionamento dos detectores a gás, dos detectores que funcionam a partir da luminescência estimulada opticamente, dos detectores de estado sólido e de cintilação; dosímetros termoluminescentes; tomografia helicoidal; funcionamento do aparelho da RMN, da PET, da SPECT; dos radiofármacos e dos radioisótopos. 
Cabe lembrar que a análise foi feita a partir de respostas de apenas cinco alunos. Com outros alunos, ou com mais alunos, os indícios poderiam ser diferentes. Não há aqui nenhuma intenção de generalizar nada. Apenas ilustrar.

\section{Considerações Finais}

Para identificar os conhecimentos prévios que os alunos possuem, um dos caminhos é a construção de questionários validados e fidedignos. Pensando deste modo, construiu-se, validou-se, calculou-se a fidedignidade de um instrumento e apresentou-se o mesmo no presente artigo. A partir disto, outros pesquisadores podem utilizar tal instrumento em suas pesquisas, quando visem identificar conhecimentos prévios que os alunos possuem, relativos à Física aplicada na Medicina. Tal questionário também pode ser utilizado para comparar os conhecimentos dos alunos antes e após a instrução.

Considerou-se esse trabalho fundamental para a pesquisa que originou uma dissertação de mestrado (Parisoto, Moreira, 2011). Pois é indispensável, para ensinar de forma potencialmente significativa, saber os conhecimentos prévios que os alunos possuem, para que se possa ensinar de acordo com eles, ou seja, ancorando os conhecimentos novos aos já existentes na estrutura cognitiva dos alunos (subsunçores). Também utilizaram-se os resultados da pesquisa para não ensinar conhecimentos que os alunos já possuíam, para que as aulas não se tornassem maçantes, mas sim atrativas, favorecendo a aprendizagem significativa, já que um fator relevante para isto é a motivação do aluno em aprender.

\section{Referências}

Aiziczon, Beatriz; Cudmani, Leonor. Ondas, sonido y audición: ideas previas de los estudiantes em Ciências Médicas. Caderno Brasileiro em Ensino de Física, v. 24, n.3, p.360-399, nov. 2007. Disponível em:

<http://www.periodicos.ufsc.br/index.php/fisica/article/view/6242/5793>. Acesso em: 02 de mar. 2010.

Ausubel, David Paul. Retenção e aquisição de conhecimento: uma perspectiva cognitiva. Lisboa: Plátano, 2002.

Bravo, Bettina M.; Rocha, Adriana L. Los modos de conocer de los alumnos acerca de la visión y el color: síntesis de resultados. Revista Electrónica de Enseñanza de las Ciencias, v. 7, n.3, p. 582-596, set. 2008. Disponível em: <http://reec.uvigo.es/volumenes/volumen7/ART5_Vol7_N3.pdf>. Acesso em: $02 \mathrm{de}$ mar. 2010. 
Capplletto, Eliane; Prestes, Michely; Santos, Arion de Castro Kurtz dos. Concepções dos Estudantes sobre Radiações. XI Encontro de Pesquisa em Ensino de Física, p. 112, 2008.

Costa, Luciano Gonsalves; Costa, Ana Paula Astrath. O ensino de Física das radiações na formação de auxiliares de enfermagem e atendentes de consultórios odontológicos: sondagem de concepções sobre Raios-X com enfoque na prevenção e tecnologia.

Ciência \& Educação, v. 8, n.2, p. 161-165, set. 2002. Disponível em: <http://www2.fc.unesp.br/cienciaeeducacao/viewarticle.php?id=194\&layout=abstract $>$. Acesso em: 2010-03-02.

Kortemeyer, Gerd. The Challenge of Teaching Introductory Physics to Premedical Students. The Physics Teacher, v. 45, n.9, p. 552-556, set. 2007.

Moreira, Marco Antonio; Rosa, Paulo Ricardo da Silva. Uma Introdução à Pesquisa Quantitativa em Ensino. Texto de apoio (não publicado), Porto Alegre, 2002.

Moreira, Marcos Antonio. Aprendizagem Significativa Crítica. Porto Alegre: Instituto de Física da UFRGS, 2005.

Parisoto, Mara Fernanda; Moreira, Marco Antonio; Moro, José Tullio. (2011) Uma revisão da literatura sobre Física aplicada à Medicina, no contexto do ensino.

Submetido à publicação.

Parisoto, Mara Fernanda; Moreira, Marco Antonio. O Ensino de Conceitos do Eletromagnetismo, Óptica, Ondas e Física Moderna e Contemporânea Através de Situações na Medicina. 2011. 447f. Dissertação (Mestrado em Ensino de Física) Programa de Pós-Graduação em Ensino de Física, Universidade Federal do Rio Grande do Sul, Porto Alegre.

Valadares, Jorge. Moreira, Marco Antonio. A teoria da aprendizagem significativa: sua fundamentação e implementação. Coimbra: Edições Almedina, 2009.

West, John B. Challenges in Teaching the Mechanics of Breathing to Medical and Graduate Students. Advances in Physiology Education, v. 32, n. 1, p. 177-184, dez. 2004. 